\title{
Mining Rock Mass Models - A Methodology for Collecting, Processing and Presenting Geotechnical Data in Three Dimensions
}

\author{
C.R.W. Seymour Dempers \& Seymour Pty Ltd, Australia \\ G.D. Dempers Dempers \& Seymour Pty Ltd, Australia
}

P.A. Jenkins Dempers \& Seymour Pty Ltd, Australia

\begin{abstract}
A comprehensive three dimensional geotechnical model is fundamental to any pit slope design. This paper details a methodology for the collection, processing and spatial interrogation of geotechnical data that enables a robust three dimensional Mining Rock Mass Model (MRMM) to be constructed. The modelling techniques used to create the MRMM have been refined through their use on over forty mining projects that range from greenfields studies to mature producing mines. Case studies that illustrate the use of the MRMM and its versatility for the appreciation of geotechnical data as well as timely integration into the mine planning process are presented for a variety of open pit applications.
\end{abstract}

\section{Introduction}

Large volumes of geotechnical data are often collected during the life of a typical open pit project but this data is rarely ever effectively applied to represent the rock mass conditions across the project. Therefore as a concept, the MRMM was specifically developed to enable the better appreciation of rock mass conditions and the three dimensional variability across a project, hence optimising the use and application of available geotechnical data. Through application on a wide range of projects, a rigorous MRMM methodology has been developed which ensures that only reliable, validated data is used.

The MRMM allows all the logged values and calculated geotechnical parameters for the major rock classification systems to be represented in three dimensional block models. These models are constrained by the available geological and structural data and are analogous to a resource block model in the way that they can be viewed and incorporated into the planning process. The processing and classification of the geotechnical data for the MRMM is based on the prevailing rock mass conditions. This allows the variability of rock mass conditions within and across individual lithological/geological/structural units to be identified and so unique geotechnical domains may be more readily identified than by traditional means of data manipulation and display.

The MRMM methodology can be broken down into the following steps, as described in this paper.

- Data collection - Principally geotechnical logging data of drillhole core, as documented here, though other forms of data (field mapping of rock mass and structure as well as structural logging of core) may also be incorporated into models.

- Data Validation - Although not covered in great detail in this paper, this is an important aspect of the methodology as consistency of interpretation between different personnel conducting the logging must be ensured. Core photographs are retained for this purpose and this step can be time consuming, but is vital as poor data input can lead to an unreliable model output.

- MRMM construction.

- MRMM interrogation.

\section{Data Collection}

Rock mass data for a new or greenfield project normally comprises geotechnical logs of drill core. The data collected is in the form of a drillhole log (Hole-id, From, To, Geotechnical value1, Geotechnical value2, etc.) 
and therefore can be stored and processed using custom macros in existing mining software packages (Datamine, Surpac, Gemcom etc.) or processed with spreadsheet macros. The end product is then a database table containing the logged and processed geotechnical data.

There are many different forms of geotechnical logging data collection that range from established methods through to project/outcome specific templates developed 'in-house'. The format and legend for logging that is presented in this paper has evolved with development of the MRMM. It differs from other logging schemes in that it is designed to help highlight rock mass variability and in particular those regions or conditions in the rock mass that are likely to be problematic for design purposes.

Only those aspects of the logging scheme that are unique to the MRMM methodology are described here.

\subsection{Geotechnically Logged Intervals}

The logging of individual drill holes uses the Domain Logging methodology as initially described by Dempers (1991). Selecting the geotechnical intervals or domains is the first step in the logging process. A domain can be many metres in length or less than a metre and these are determined from significant lithological boundaries which are then further sub-divided according to geological structure, weathering, hydrogeology, veining and alteration within those major lithological boundaries. In addition, the drill core domains are selected according to geotechnical characteristics by grouping together rock which displays similar geotechnical properties for example uniaxial compressive strength, condition of discontinuities, Rock Quality Designation (RQD), number of discontinuities per fracture angle, orientation of discontinuities etc.

The logging scheme ensures that sufficient data is collected within each domain (logged interval) to allow a rating determination or ranking for all of the major rock mass classification systems to be calculated, i.e. Rock Mass Rating (RMR) and its derivatives Geological Strength Index (GSI) and Rock Tunnelling Quality Index (Q). As such, the codes used for data collection are based on Barton et al. (1974) and Laubscher (1990).

\subsection{Fracture Characteristics}

The logging of joints per geotechnical domain is divided into three groups based on the fracture alpha angle, i.e. the angle between the fracture plane and the core axis. The groupings used are $0-30^{\circ}, 30-60^{\circ}$ and $60-90^{\circ}$, with a fourth $0-90^{\circ}$ grouping being used for broken zones where the alpha angle cannot be readily identified. The same information, including a fracture count, is recorded for each fracture grouping.

Only obvious pre-existing structures that are continuous planes of weakness right through the core stick are counted. In places where there is extensive fracturing $\left(0-90^{\circ}\right.$ grouping) and fractures cannot be easily counted, then one of three fracture count numbers is applied:

Highly fractured and broken rock that does not display any joint surfaces is given a fracture count of 1000 (fragments 'corn flake' sized or less).

Ground that is fractured to a lesser degree is given a fracture count of either 500 ('match-box' to corn flake sized fragments on average) or 250 (larger than match-box sized).

The same data is then logged for each fracture angle grouping for which a fracture count is given and this consists of roughness descriptors as well as fracture infill type, thickness and joint wall alteration.

\subsection{Matrix Codes}

These codes are an additional descriptor that is used to help highlight conditions that are of geotechnical significance. As such, they are not used for every logged interval but should always be recorded where a 250 , 500 or 1000 fracture count has been used.

The matrix codes commonly used are:

$\begin{array}{ll}\text { M1 } & \text { Fault (discrete). } \\ \text { M2 } & \text { Shear zone. } \\ \text { M3 } & \text { Intense fracturing. }\end{array}$




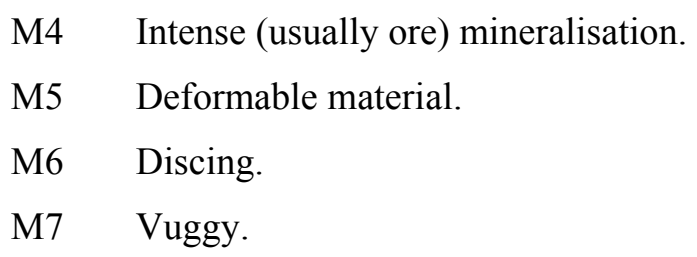

Additional project specific matrix code are also used where they are appropriate and may be used for specific types of pervasive alteration, veining or unique geotechnical features within the rock mass.

\section{MRMM Modelling Process}

The raw logging data is used to calculate various geotechnical parameters and rock mass rating values which are converted into block models using the resource estimation routines currently available in geological software packages. The procedure is summarised in the following section and commences with the compilation of the raw data as shown in Figure 1.

The raw data is loaded into the geological software package as a drillhole "assay" table, an example of which is shown in Figure 2. If the raw data was processed by spreadsheet, the processed values would also be loaded. Alternatively the data is processed within the geological modelling software using customised macros.

The drillhole data is composited into regular intervals within each logged domain. Composites should not combine data from different domains. The composite size is a function of the block model size and as a rule of thumb the maximum composite should not exceed half the block height. For example if the block height is $10 \mathrm{~m}$ and the domain length is $17.5 \mathrm{~m}$ the composites would consist of $3 \times 5 \mathrm{~m}$ plus $1 \times 2.5 \mathrm{~m}$ composites. Block model dimensions are project specific and are dependent on the main geotechnical controls (for example lithology, structure etc.). A massive deposit could have a larger block size compared to a thin vein deposit.

The composite data is then used to estimate block values using the resource evaluation modules (kriging, inverse distance etc.) within the geological software package. The block model estimation process should be constrained by the likely controls on the rock mass data. The constraints are project specific and could include weathering profiles, lithology, foliation, bedding, major structural orientation etc. This process requires an understanding of the controls on rock mass quality for the project and involves a number of iterations. Typically this process may commence using weathering profiles and lithology as primary constraints. Further interrogation of the model may reveal unique features that require separate domains to refine the block estimate. In most cases the iterative process involved with developing the model will also increase the understanding of the rock mass quality and the variation across the project. During the process, each domain is estimated independently using only raw, composited data for that particular unit. This process is illustrated in the following figures.

\section{MRMM Model Interrogation}

Rock is not homogenous and may be quite variable with regard to rock mass conditions. The variability can be as a result of major geological structures, large faults zones, areas of closely spaced jointing, geological structures carrying water, weak rock, intense alteration, extensive rock bridge and weak rock.

The reason for the variability can be identified and visualised in the MRMM and each distinct zone can be individually domained to reflect the variability.

Rock testing can then be based on the variability, and each domain can be tested as opposed to testing per rock type. Test samples can be taken from these domains and from any major structures or joint set identified. After testing has been completed, the domains can be calibrated against test data and observation and directly exported to two dimensional limit equilibrium and three dimensional numerical models. 


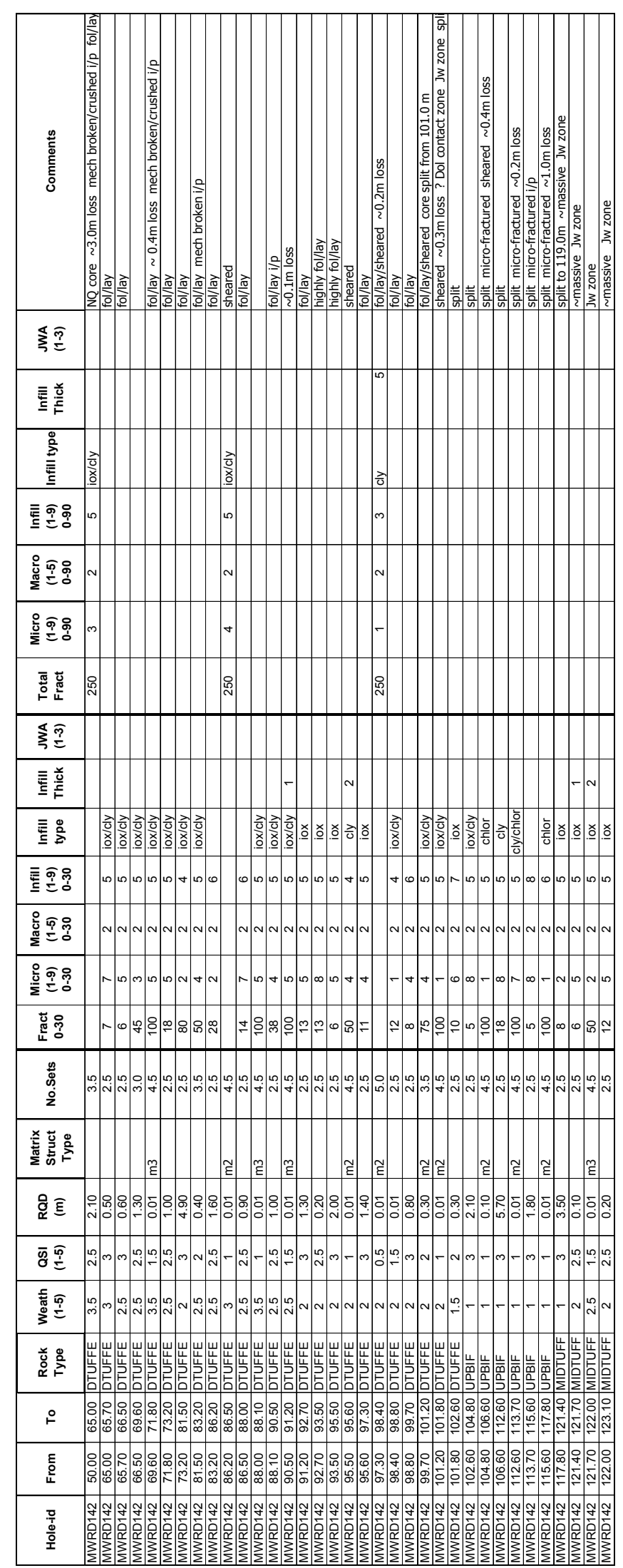

Figure 1 Typical rock mass $\log \left(\right.$ note $30-60^{\circ}$ and $60-90^{\circ} \log$ not shown) 


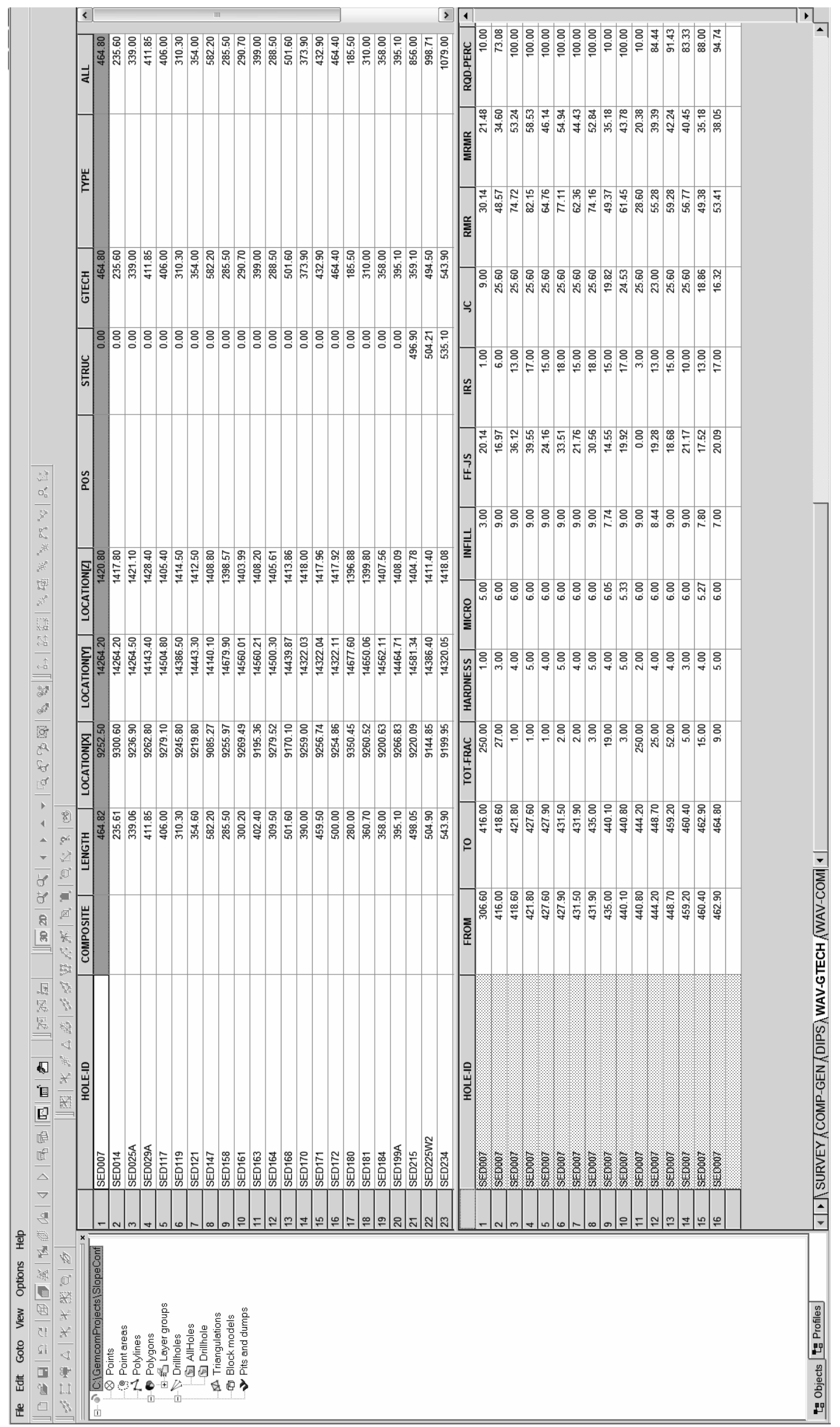

Figure 2 Geotechnical data stored in an assay table 


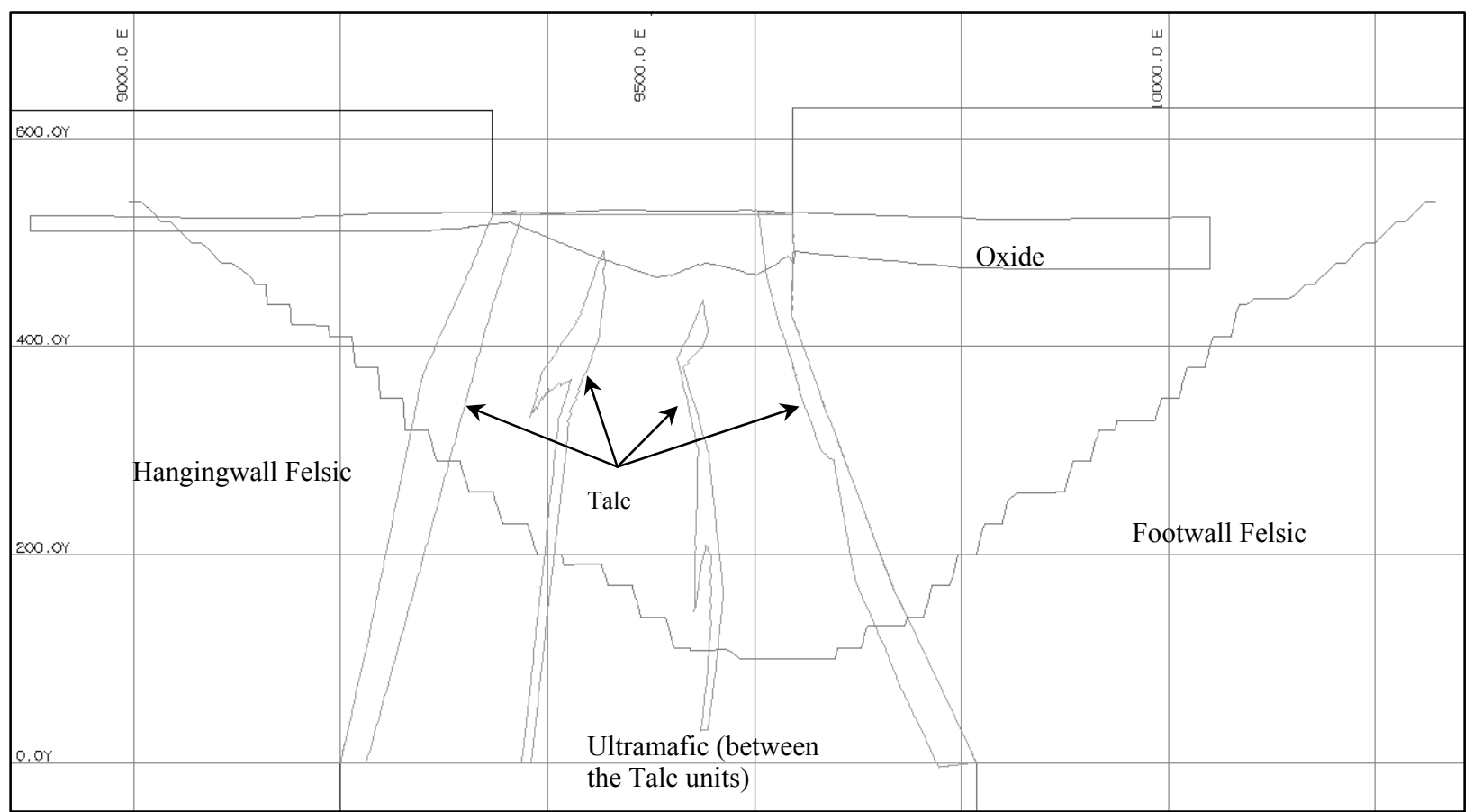

Figure 3 Cross section showing the first pass model with initial domains

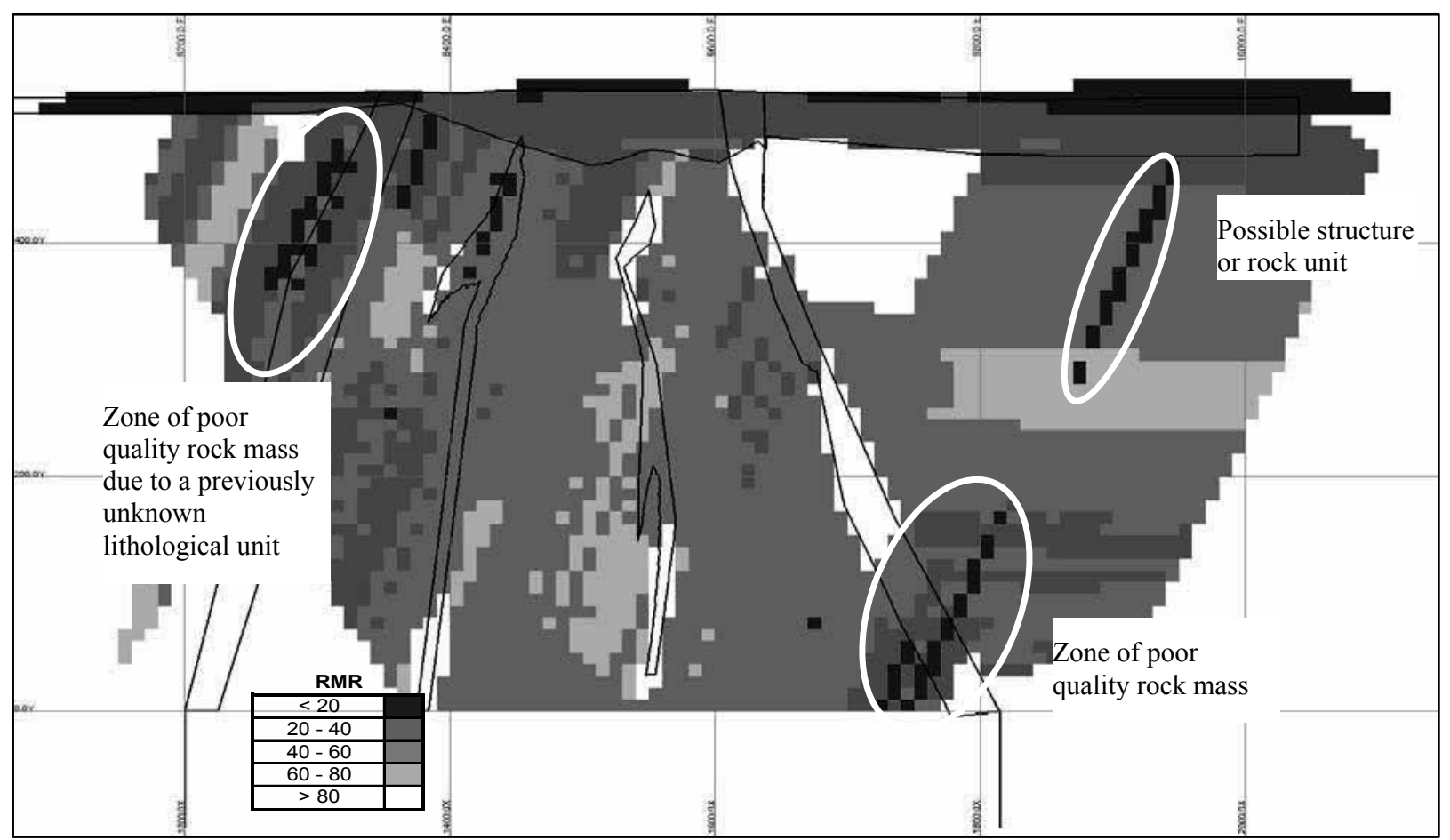

Figure 4 Second pass estimate with lithological control and the estimation envelopes oriented to the dip of the individual domains 


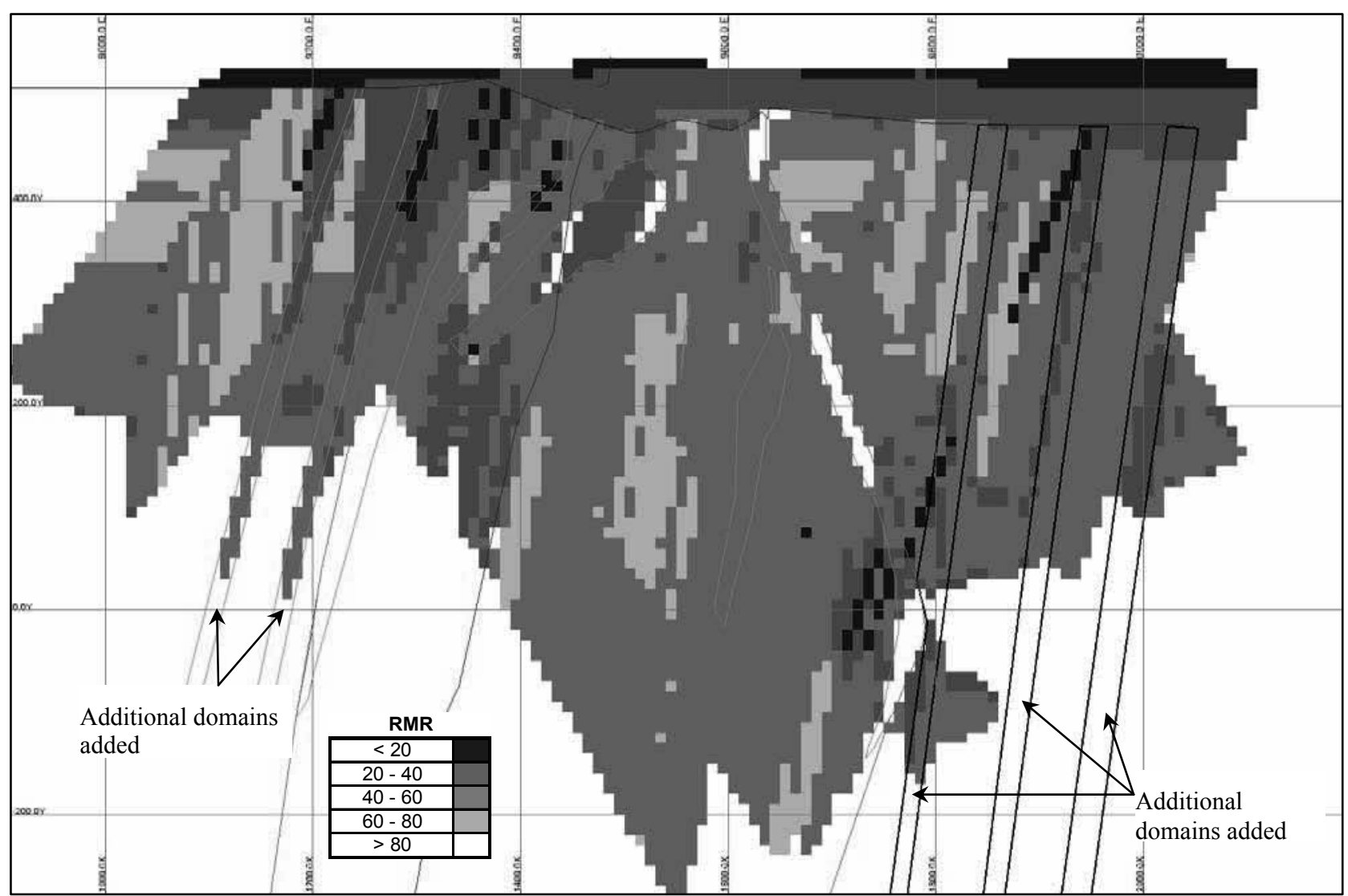

Figure 5 Final estimate with additional geotechnical domains, lithology and weathering profiles and the estimation envelopes oriented to the dip of the individual domains

This is illustrated in case studies where the rock was thought to be of one particular type whereas interrogation of the MRMM identified the presence of major structure, different rock units and zones of extremely soft rock caused by alteration. In the preceding example (Figure 3 to Figure 5) the variation in rock mass quality is apparent and can be seen as the model is developed. With each pass of the modelling process, additional domains were added to model structure and rock units. Variation in rock mass quality is also apparent in the following case study. For this project, the hangingwall lithology had been defined as a single rock unit. During the course of developing the MRMM, it became apparent that the hangingwall comprised a number of units each with quite different properties. This is shown in Figure 6.

Understanding the cause of the variation in rock mass quality is very important and the MRMM can be used to evaluate the variable zones. In addition to the classification ratings (RMR, MRMR, GSI, Q etc.), individual geotechnical parameters are also modelled and interrogation of these models will aid understanding of the rock mass. The critical parameters include:

- Joint intensity, calculated from RQD/Jn and fracture frequency represents the structure of the rock mass and gives a measure of block size (McCracken and Stacey, 1989).

- Discontinuity shear strength, determined from micro roughness and joint infill, represents the roughness and frictional characteristics of the joint wall and infill material (McCracken and Stacey, 1989).

- Fracture frequency.

- Rock strength. 


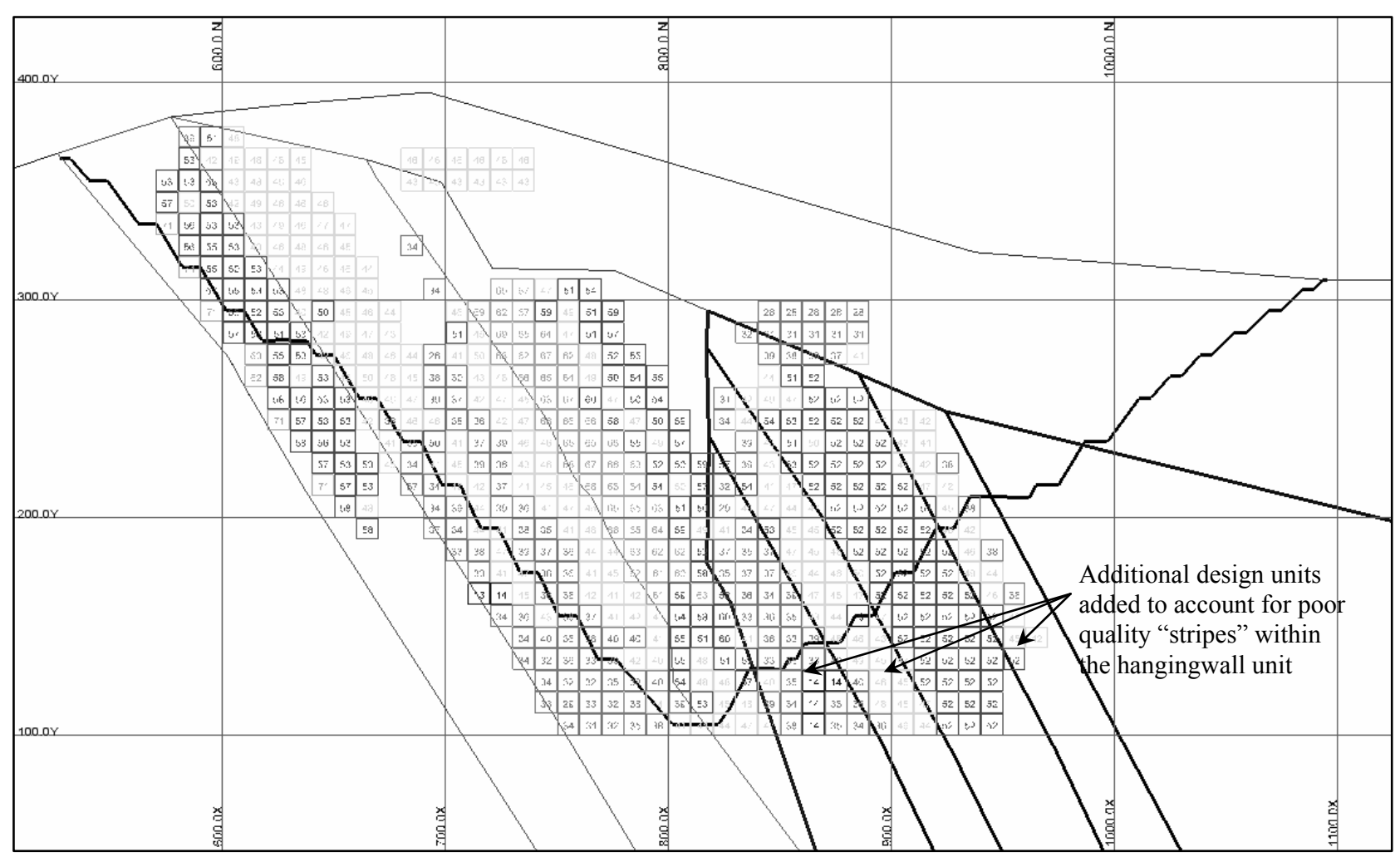

Figure 6 Variation in rock mass quality within a single lithological unit

The classification of critical geotechnical parameters range from very poor to very good as shown in Table 1.

Table 1 Classification of geotechnical parameters

\begin{tabular}{lccccc}
\hline Parameter & Very Poor & Poor & Fair & Good & Very Good \\
\hline Joint Intensity (RQD/Jn) & $<4$ & $4-8$ & $8-15$ & $15-25$ & $>25$ \\
Joint shear strength (Jr/Ja) & $<0.5$ & $0.5-0.75$ & $0.75-2$ & $2-3$ & $>3$ \\
Fracture Frequency (FF/m) & $>15$ & $3-15$ & $1-3$ & $0.3-1$ & $<0.3$ \\
Rock Strength (MPa) & $<25$ & $25-50$ & $50-100$ & $100-160$ & $>160$ \\
\hline
\end{tabular}

Figures 7 and Figure 8 show the variation in two critical geotechnical parameters (Rock Strength and Joint Shear Strength Jr/Ja). In this example the rock strength is classified as Very Good (UCS $>160 \mathrm{MPa}$ ) whereas the joint shear strength is Poor to Fair $(\mathrm{Jr} / \mathrm{Ja}<2)$.

These critical parameters and the influences are recognized and planned for in the preliminary stage of the pit slope design. Additional drillholes can then be planned to investigate these characteristics and "hot spots" in the MRMM. Pit slopes and pit infrastructure such as haul ramps can be planned during the early stages before rigorous analyses are commenced. By interrogating the MRMM, preliminary pit slope angles are visualised in three-dimensions and the pit slope design can take cognisance of the poor quality zones within the rock mass. 


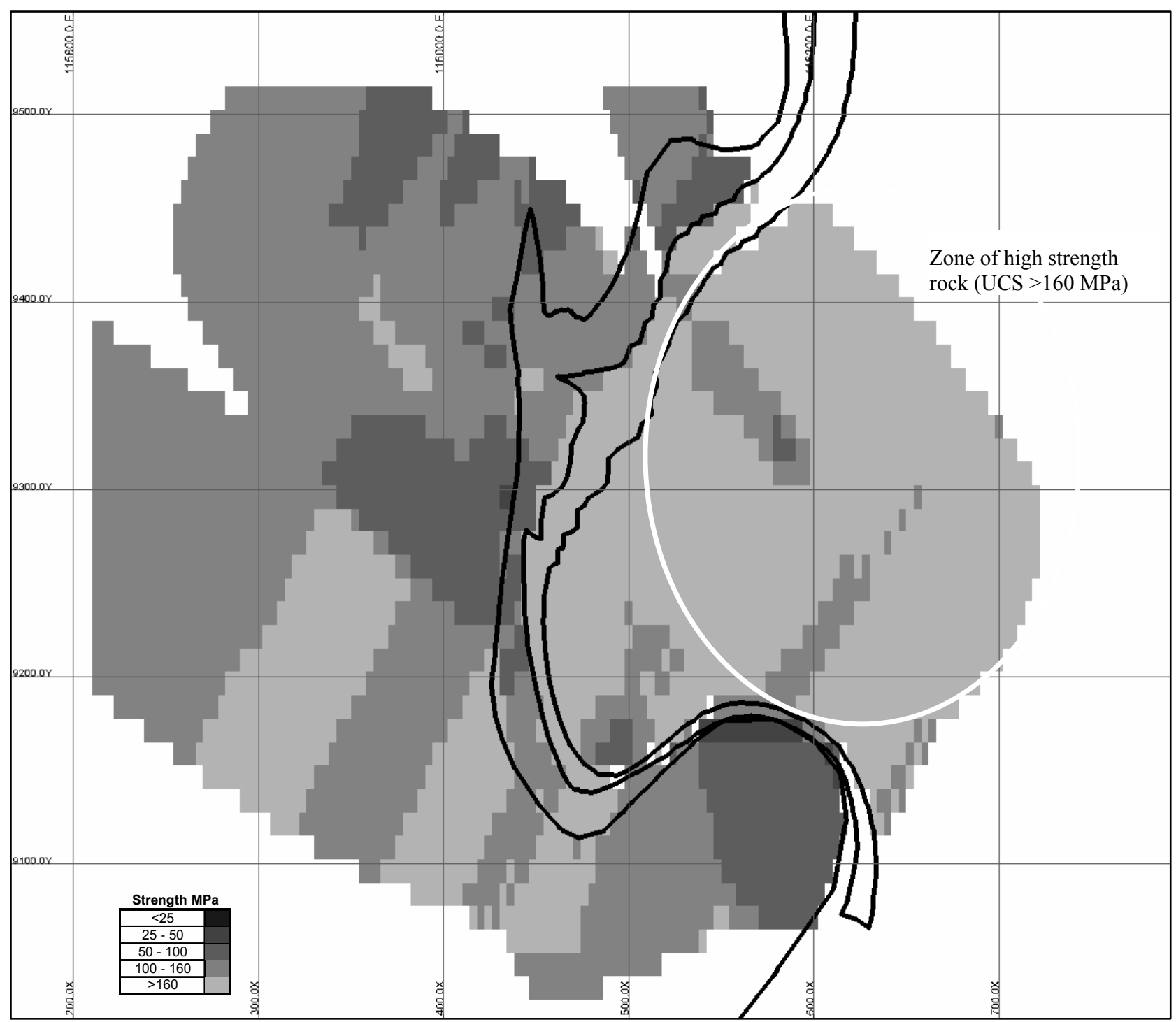

Figure 7 MRMM showing rock strength

In addition to zones of poor quality, structure is very important in controlling the behaviour of a rock mass and is responsible for the majority of wall failures in pits. The location and nature of structure in terms of persistence, dip, surface conditions and integrity has a big influence on pit slope stability and design configurations.

Identifying these features early in project life can be very beneficial in that design considerations can be made that account for these features.

In most cases, during the early stages of a project, the geological controls of these structures with regard to geotechnical issues can be quite limited. It is often evident that in the exploration phase of a project the geological structures which significantly impact pit design are not well recorded (if at all) because the focus of data collection has been targeted towards the orebody and not the pit walls.

The MRMM can be used to identify potential structures very early on so that they can be targeted for further investigation. 


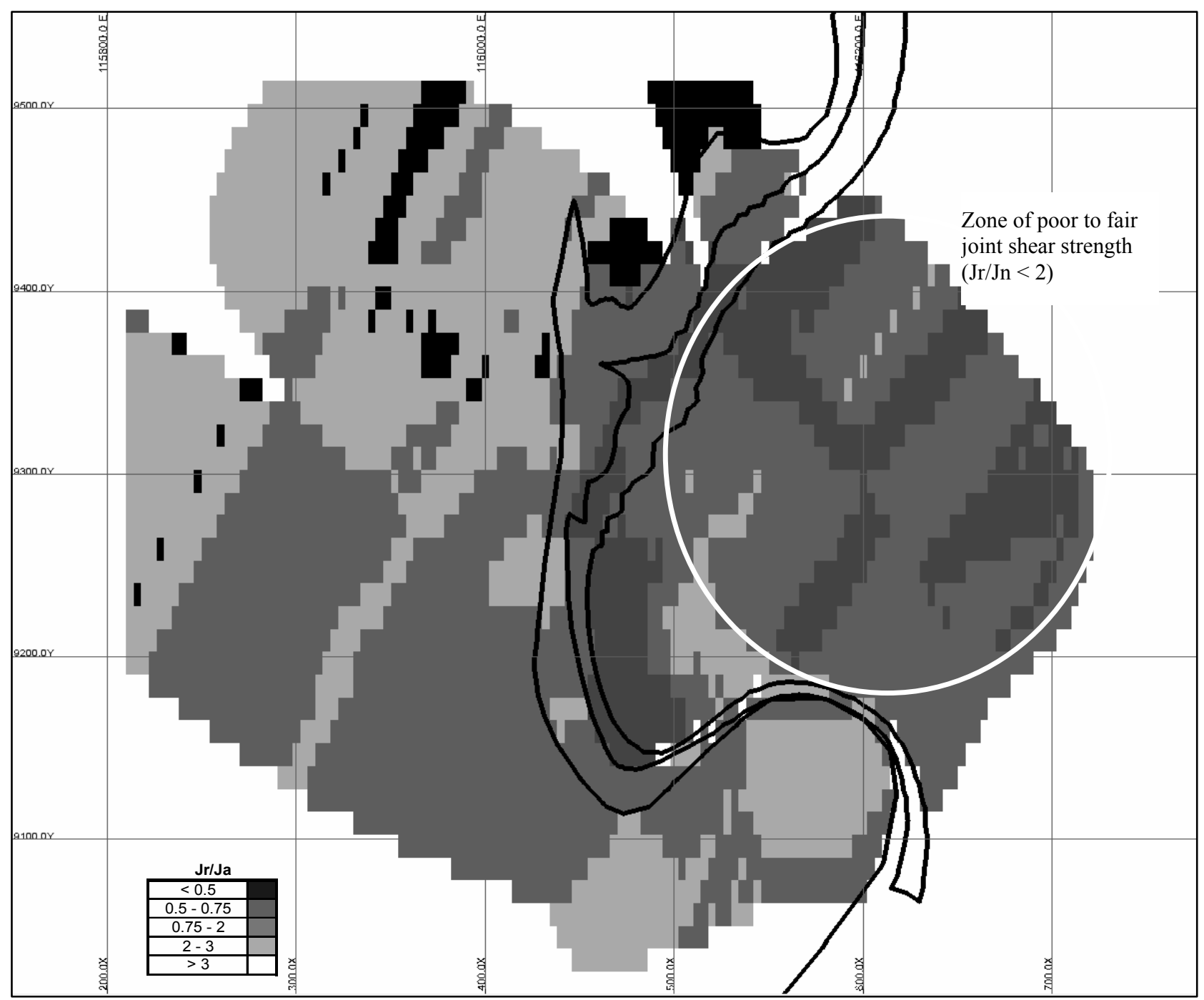

Figure 8 MRMM showing joint shear strength

The modelling of structures is carried out by identifying major features from the matrix zones and structural data. These zones are logged for geotechnical characteristics for example fracture frequency, joint condition and infill condition.

The geotechnical database is then interrogated to evaluate major structures. This analysis involves applying search criteria to identify structure with geotechnical significance. The points that meet the criteria are shown in the example given in Figure 9. These potential features consist of material that is intensely fractured, highly polished and persistent with an interval greater than $1 \mathrm{~m}$. Some of the features coincide with existing known structures also shown in Figure 9. The remaining points were investigated and two additional structures were interpolated as shown in Figure 9. 


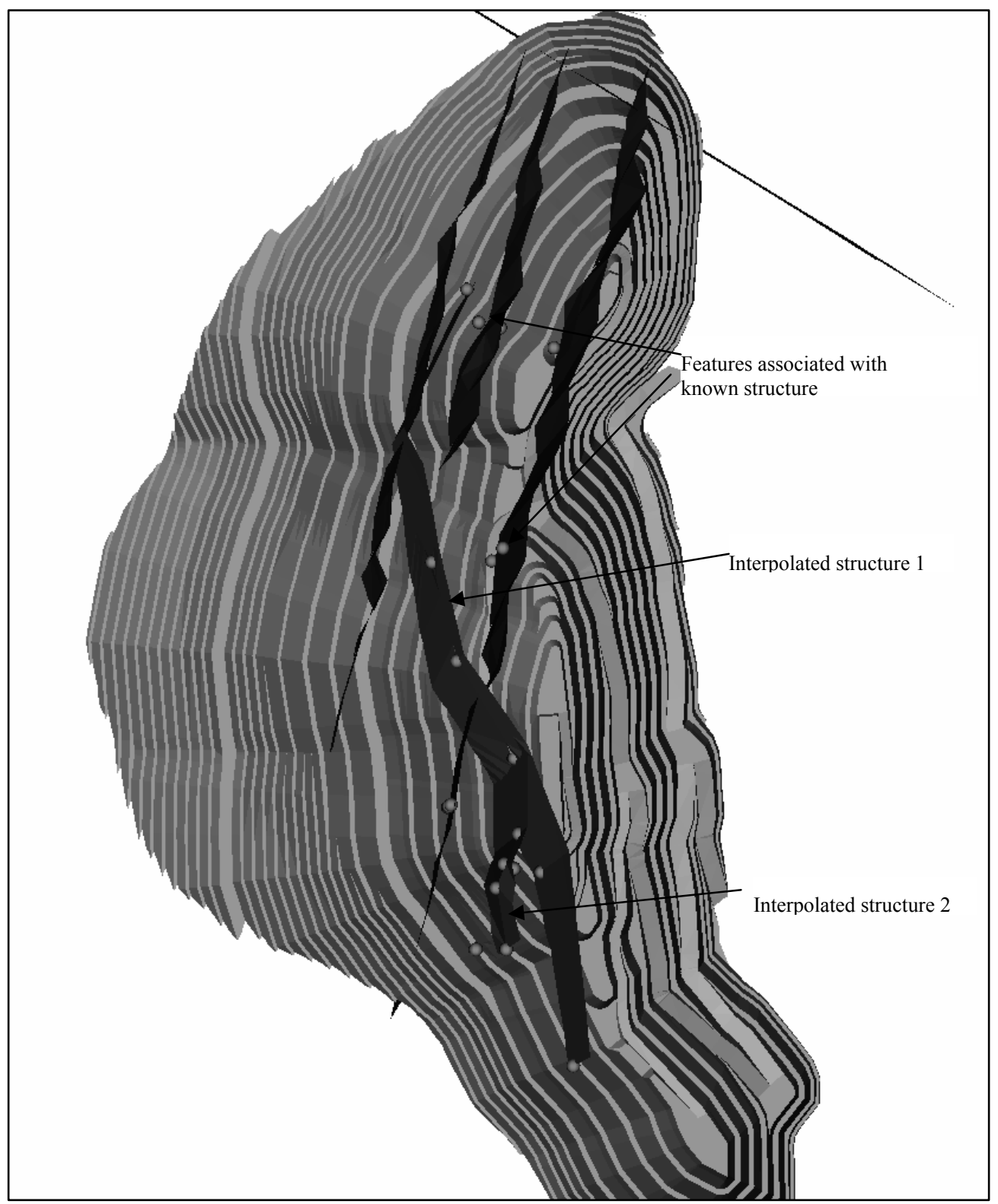

Figure 9 Isometric view showing interpolated structures

This interpretation is carried out in tandem with stereographical interpretation of structural measurements taken either from traditional core orientation methods or where the rock is too fractured from downhole televiewer surveys.

Block models can also be used to interpret structure. In the following example a block model was created for very poor rock strength (UCS $<25 \mathrm{MPa}$ ) as shown in Figure 10. 


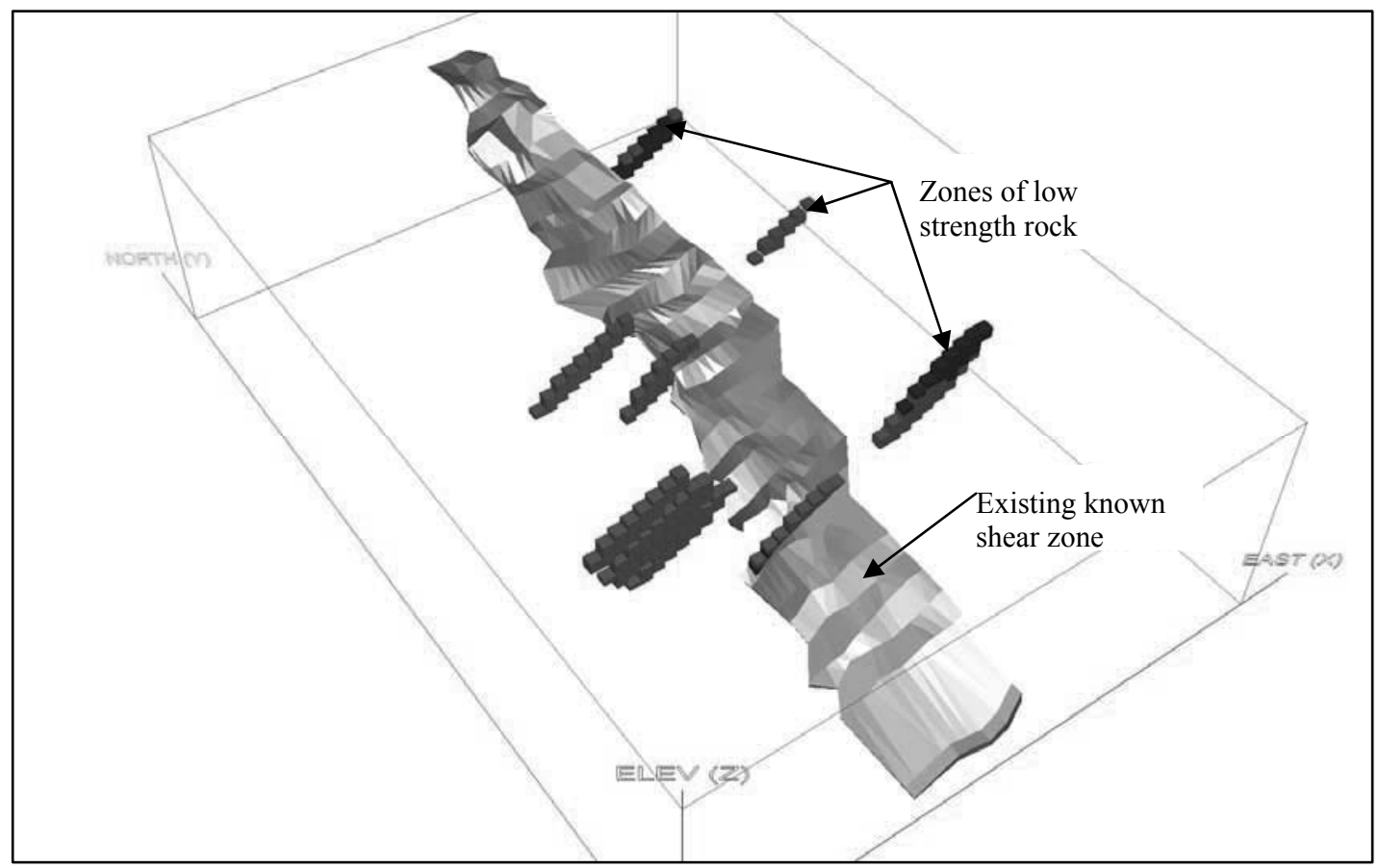

\section{Figure 10 Low rock strength block model}

By interrogating the MRMM the existing shear zone shown in Figure 10 was extended as shown in Figure 11.

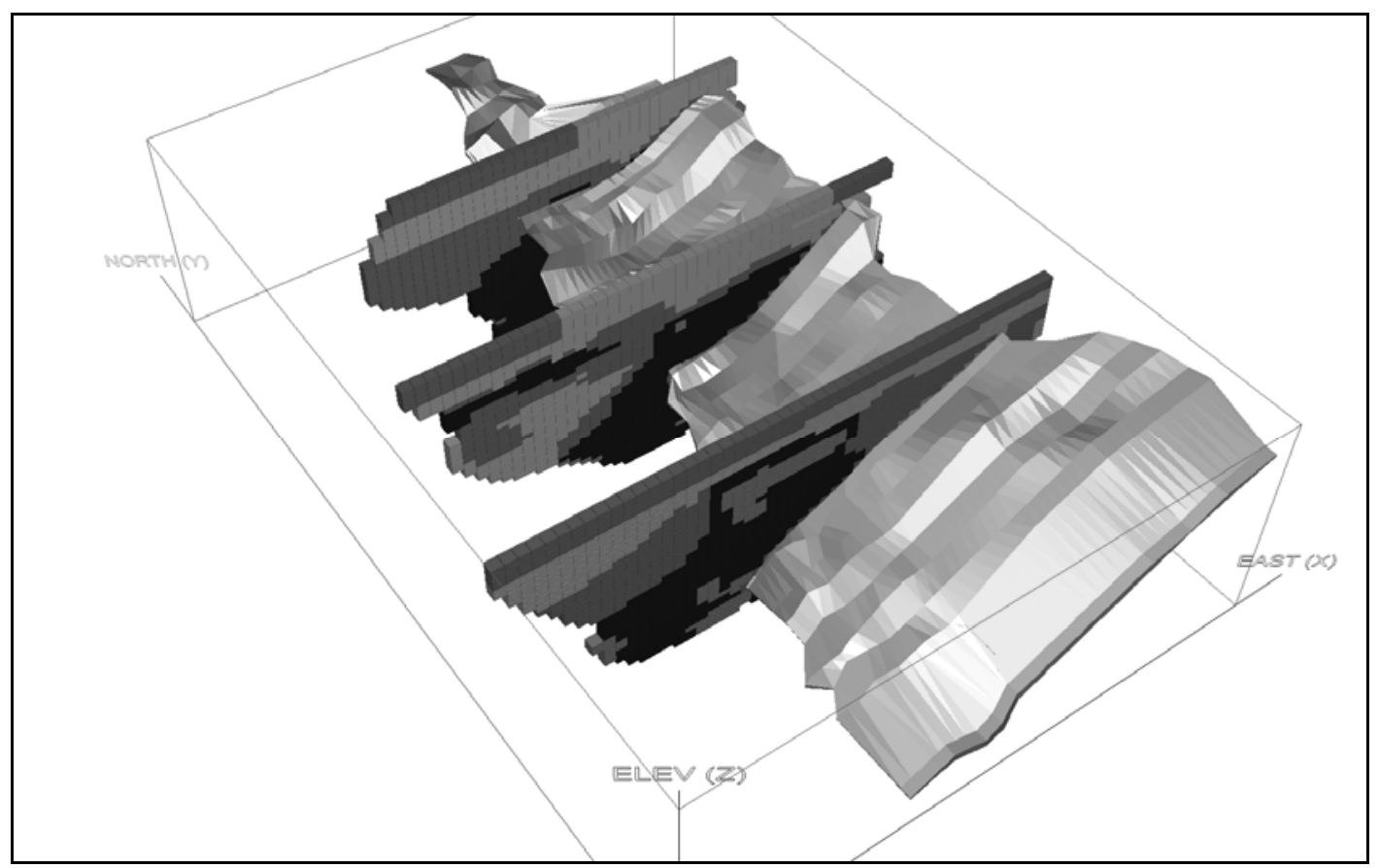

Figure 11 Shear interpreted from the MRM 


\section{Conclusions}

Mining rock mass models can be built at various stages of project life. However, greatest benefit to successful mine design and continuous operation is accrued when the MRMM is first built in the feasibility stages of a project with periodic review and update thereafter. The idealised sequence of MRMM application for a project is:

- Initial feasibility (or pre-feasibility) MRMM constructed from geotechnical logging of exploration core.

- The variability of rock mass conditions established in the initial model is then used to plan a targeted geotechnical investigation for the project.

- A second stage or updated MRMM is then constructed with the new information, in which the interpretation of project scale geotechnical domains confirmed and/or revised.

The inability to transfer geometrical and geotechnical information directly from a three dimensional model into a numerical model for slope stability analyses has been identified (Hoek et al., 2000). With the development of the MRMM, it is now possible to transfer an accurate and representative rock mass model directly to limit equilibrium and numerical models.

\section{References}

Laubscher, D.H. (1990) A geomechanics classification system for the rating of rock mass in mine design. Journal of the South African Institute of Mining and Metallurgy. Vol. 90, No. 10, pp. 257-273, October 1990.

Barton, N., Lien, R. and Lunde, J. (1974) Engineering classification of rock masses for the design of tunnel support. Rock Mechanics 6, pp. 189-236

McCracken, A. and Stacey, T.R. (1989) Geotechnical risk assessment for large diameter raisebored shafts. Shaft Engineering, Institute of Mining and Metallurgy, pp. 309-316.

Hoek, E., Read, J., Karzulovic, A. and Chen, Z.Y. (2000) Rock slopes in civil and mining engineering. Proc. International Conference on Geotechnical and Geological Engineering, GeoEng2000, Melbourne, 19-24 November.

Dempers, G. (1991) Optimal usage of exploration core for geotechnical purposes. Young Geotechnical Engineers Conference, Stellenbosch University. 